\title{
Formation and Stability Study of Nano-Emulsions: BTX- Separation
}

\author{
Jaydeep M. Barad ${ }^{1}$, Mousumi Chakraborty ${ }^{1,2}$ and Hans-Jörg Bart*,2,3 \\ ${ }^{I}$ Department of Chemical Engineering, S. V. National Institute of Technology, Surat- 395 007, Gujarat, India;
${ }^{2}$ Department of Mechanical and Process Engineering, TU Kaiserslautern, Germany; ${ }^{3}$ Center of Mathematical and
Computational Modeling, TU Kaiserslautern, 67663 Kaiserslautern, Germany
}

\begin{abstract}
The selective separation of aromatics (benzene, toluene and p-xylene, BTX) from aliphatic (n-heptane) is investigated using simple permeation and facilitated transport emulsion liquid membrane mechanism. The separation performances, represented by the permeation rate and separation factor, are analyzed systematically by varying the operating parameters. One of the major obstacles to the application of emulsion liquid membranes to industrial separations is the stability of emulsion globules. In the present study, stability of emulsion liquid membrane is studied by varying different parameters e.g. surfactant and feed phase concentration, stirrer speed for emulsification. Dispersion destabilisation of emulsion is detected by Turbiscan. Effects of interfacial tension on internal droplets size and size distribution are also systematically investigated. Stable emulsions under optimal conditions are used for the separation of aromatics (BTX) from aliphatic (n-heptane) in a synthetic feed mixture.
\end{abstract}

Keywords: BTX separation, emulsion liquid membranes, separation factor, droplets size, stability.

\section{INTRODUCTION}

The separation of aromatics hydrocarbons benzene, toluene and p-xylenes (BTX) from aliphatic hydrocarbon mixtures is challenging since these hydrocarbon have boiling points in a close ranges and form several azeotropes. A typical aromatic content of ethylene cracker feedstock is around $10-30 \%$. The presence of this aromatic content in the feedstock affects the running time of the cracking process and also the olefin yield. The conventional processes for the separation of aromatics from aliphatic hydrocarbons are liquid extraction, extractive distillation and azeotropic distillation but all are only economically viable if the aromatic content in feedstock is high. No feasible processes are available for the separation of aromatic and aliphatic hydrocarbons in the range below $40 \%$ aromatics in the feed mixture.

In order to develop a novel effective separation process, which is expected to be more energy saving and economical, the liquid membrane (LM) separation method has been studied. Li made the first attempt at the separation of hydrocarbons by emulsion liquid membranes (ELMs) in 1968 [1]. The separation of hydrocarbons by liquid membrane permeation is based on the selectivity, which arises from the difference in the permeation rate of individual species in the feed through the liquid membrane. The feed to be separated is first emulsified by a surfactant solution. The emulsified droplets surrounded by the surfactant solution are contacted with the receiving solvent to collect the more permeable solute.

There are number of articles available on the separation of aromatic and aliphatic compounds using ELMs [2-7]. In

\footnotetext{
*Address correspondence to this author at the Center of Mathematical and Computational Modeling, TU Kaiserslautern, 67663 Kaiserslautern, Germany; Tel: +49 6312052414; E-mail: bart@mv.uni-kl.de
}

the majority of studies, simple binary mixtures such as nhexane-benzene, n-heptane-toluene, 1-methylnaphtalenedodecane $[2,5,6]$ were separated into the original components. Egashira et al. [8] conducted a series of batch permeation runs using ELMs with binary, quaternary and multi-component hydrocarbon mixtures as feeds and they found that the process could remove aromatics effectively from the reformate to yield a reformate of low-aromatics. Kim et al. [9] conducted the study of permeation experiments of aromatics from an aromatics-nonaromatics binary hydrocarbon mixture in liquid surfactant membrane using saponin as surfactant and estimated the mass transfer coefficient using a simple correlation that consisted of the dimensionless stirring time and the solubility of the aqueous membrane phase. Chakraborty and Bart [10] used $\mathrm{Ag}^{+}$as a carrier to extract the toluene from a mixture of toluene and nheptane. Actually the aromatic species permeate through the aqueous phase due to the formation and diffusion of $\mathrm{Ag}^{+}-\pi$ complexes. They found that the membrane stability of this system is low owing to $\mathrm{Ag}^{+}$in the membrane phases. An increase in surfactant concentration to more than $0.5 \mathrm{wt} \%$ in the membrane phase is very effective in preventing membrane breakage. Chakraborty et al. [11] also used unsubstituted $\alpha$-cyclodextrin $(\alpha \mathrm{CD}), \beta$-cyclodextrin $(\beta \mathrm{CD})$ and two substituted CDs as a carrier in o/w/o-type ELMs and found high separation factor and a higher mass transfer rate for the separation of toluene from n-heptane due to formation of inclusion complex.

Although all of them achieved high separation factor and mass transfer rate but the problem that inhibits the application of this technology in industrial equipment is the loss of extraction efficiencies that often occur in these systems due to lack of stability of the emulsion globules. Many researchers carried out stability study of emulsion [1215] using $w / o / w$ emulsion. However, very few have been studied on o/w/o system [3,10]. Krishna et al. [3] used benzene-n-heptane mixture and l-methylnaphthalene- 
dodecane mixture as a feed and carried out ELMs study in a batch stirred cell to determine the permeation rates. They developed a mathematical model which considered the overall process of hydrocarbon permeation through liquid membranes as a combination of two processes in parallel, a non-selective transfer due to emulsion breakage and a selective diffusional transfer through the membrane. Chakraborty and Bart [10] found that incorporation of strong electrolyte $\left(\mathrm{Ag}^{+}\right.$as a carrier) in the aqueous (membrane) phase increases membrane breakage, resulting into the rapid transfer of internal feed phase to external phase. They measured fractional breakage using a water-insoluble dye tracer technique.

Actually in oil/water emulsions, stabilized by ionic surfactants, attractive and repulsive electrostatic forces are mainly responsible for their stability. The well known DLVO theory explains the role played by these forces on emulsion stability, although certain modifications are necessary when the theory is applied to the microscopic oil droplets stabilized by adsorbed emulsifying agents. The application of this theory further demands knowledge of the London dispersion forces operating in the system. The theoretical calculation of the London constant does not always give sufficiently reliable results for experimental behavior to be predicted with enough precision [16]. Indirect methods of approach, such as those based on measurements of stability and electrokinetic potential, are more favorable and experimentally applicable.

In the present study, Turbiscan has been used to monitor emulsions and dispersions in the kinetic studies of emulsion stability. Properties such as interfacial tension, drop size distribution, photomicrographs and zeta potential are also analysed to evaluate emulsion stability. Stable emulsion, comprising water as membrane phase with sodium dodecyl sulphate (SDS) as surfactant and BTX and n-heptane mixture as feed phase, is used for the separation of aromatics from aliphatics.

\section{EXPERIMENTAL}

\section{Materials}

Mixtures of BTX and n-heptane are chosen as the hydrocarbon feed. Feed mixtures and n-dodecane (receiving phase), supplied by Merck, India and Germany, having purity greater than 0.99 mass fraction are used without further purification. All ELMs experiments are carried out at standard temperature $298 \mathrm{~K}$. An aqueous membrane solution is prepared by dissolving SDS (supplied by Merck, India and Fluka, Germany), an emulsifying agent, whose values for the hydrophile-lipophile balance (HLB) are larger than 10, in distilled water. Silver nitrate and $\beta$-cyclodextrin $(\beta C D)$ (purity $\geq 98 \%$ ) purchased from Merck, India, are used as carriers in the membrane phase.

\section{Apparatus and Procedure}

After the feed (15-45 wt $\%$ of BTX equiweight mixture and $85-55 \mathrm{wt} \% \mathrm{n}$-heptane) has been well mixed, the feed and surfactant solution at a specified concentration are emulsified using an ultraturax T25 homogenizer (IKA, Germany), a high speed mechanical stirrer, with speed variation from $6500 \mathrm{rpm}$ to $24000 \mathrm{rpm}$. Emulsion stability is checked varying different parameters and stable emulsion is then dispersed in the solvent (n-dodecane) phase. The agitating speed of the mixer is controlled by a speed controller at $300 \mathrm{rpm}$ and monitored by a tachometer. Samples of about $2 \mathrm{ml}$ are withdrawn from the extractor at different intervals of time and are filtered through a sintered glass plug to separate emulsion and receiving phase.

After a specified contact time, the emulsions and the solvent are separated from each other by gravity difference in a settler. The separated emulsions are broken by heating and samples for analysis are taken from the solvent and the broken emulsions. The recovered solvent and surfactant solution are reused in the mixer and emulsifier, respectively.

The concentrations of each component are measured by a PerkinElmer gas chromatograph with a Restek-Stabilwax column (60 m x $0.32 \mathrm{~mm} \times 0.5 \mu \mathrm{m})$.

\section{Measurement of Physical Properties of Emulsion}

Interfacial tensions are measured by the $\mathrm{Du}$ Noüy ring method with a tensiometer. The lower phases are aqueous SDS solutions (membrane phase) in all cases at different concentration. The concentrations of BTX and n-heptane (feed phase) are varied in the upper phase. Oil and water phases are equilibrated before the interfacial tension measurements.

Emulsion stability is analyzed using transmission and back scattering profiles, scanning the emulsion sample by light rays of $880 \mathrm{~nm}$ wavelength using Turbiscan classic MA 2000 (Formulaction, France).

Dispersed drop size measurements are carried out within few minutes after preparation of emulsion. Samples $(1 \mathrm{ml})$ are taken and diluted in n-dodecane $(3 \mathrm{ml})$. To improve the optical transparency of the dispersed emulsion, most of the emulsion drops are adsorbed by contacting the drop with filter paper, leaving few emulsion drops on the glass slide. The sample is covered with a thin cover glass and the photomicrographs are taken using Diastar Microscope and Photostar Camera system (Cambridge Instruments, USA).

Internal droplets sizes, drop size distribution of the $(\mathrm{o} / \mathrm{w})$ emulsion are measured by Acoustic \& Electroacoustic Spectrometer (model DT1200, Dispersion Technology, Inc., USA). Colloidal Silica solution (Silica Ludox, wt fraction $10 \%$ ) having mean particle diameter $28 \mathrm{~nm} \pm 5 \mathrm{~nm}$ has been used for calibration.

The zeta-potential measurements are performed using the electrophoretic light scattering method (ELS-8000, Photal Otsuka Electronics Co. Ltd, Osaka, Japan).

\section{THEORY OF SEPARATION}

\section{Separation Factor}

The relative ease of separation under the specified conditions can be expressed by the separation factor, which is defined as:

$$
\text { Separation factor }=\frac{\text { the wt.fraction of the more permeable in solvent/the wt.fraction of the more permeable in feed }}{\text { the wt.fraction of the less permeable in solvent/thewt.fraction of theless permeable in feed }}
$$


The greater the separation factor, the better is the separation of BTX and n-heptane at a given condition.

\section{Solubility of Hydrocarbons}

The polarity of different organic compounds can be measured by $\mathrm{E}_{\mathrm{T}}(30)$ scale [17]. It is found from $\mathrm{E}_{\mathrm{T}}(30)$ scale that benzene (34.3) has highest polarity. $\mathrm{E}_{\mathrm{T}}(30)$ value decreases from toluene (33.9) to p-xylene (33.1). Generally, polar hydrocarbons have a high solubility in water. In ELMs unless the water layer is very thin, the resistance of the water layer controls the selectivity. If the separation factor $\beta$ is greater than unity, it indicates BTX transfer to the solvent phase faster than $n$-heptane. Again separation factor value will further increase due to carrier-mediated $\left(\mathrm{Ag}^{+}, \beta \mathrm{CD}\right)$ transport through the formation of complexes.

\section{RESULTS AND DISCUSSION}

It has been found from the literature that more than $50 \%$ recovery of aromatics (simple permeation) and 70-80\% recovery of aromatics (facilitated transport) are possible within $10 \mathrm{~min}$ of residence time [9-11,18]. So a Back Scattering (BS) profile of any sample, scanned from the bottom $(0 \mathrm{~mm})$ to the top of the vial $(\sim 60 \mathrm{~mm})$, is carried out for the period of 10-20 min.

\section{Effect of Surfactant Concentration}

Fig. (1) shows that interfacial tension is decreasing with increasing surfactant concentration and there is no change of interfacial tension when surfactant concentration has reached its optimum value i.e. CMC of SDS is $8.06 \pm 0.33 \times 10^{-5} \mathrm{M}$ $(\sim 0.023 \mathrm{~g} / \mathrm{l}) \quad$ [19]. It is observed that the surfactant concentration in the membrane phase significantly affects the emulsion stability. With increasing surfactant concentration interfacial film strength will increase and enhance resistance to coalescence.

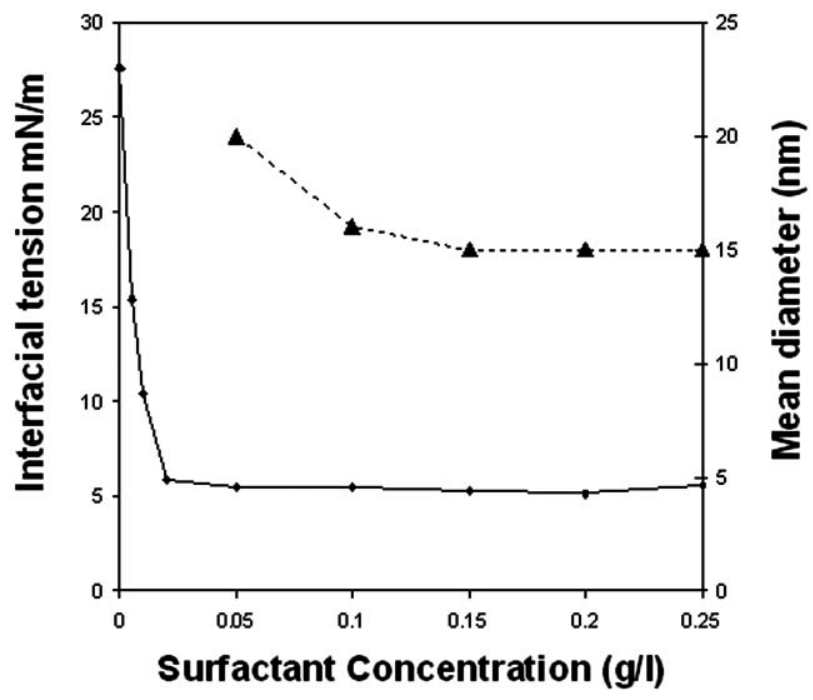

Fig. (1). Effect of surfactant concentration on interfacial tension and internal droplets mean diameter.

The droplet size distribution and mean droplet diameters of emulsions (stirrer speed $6500 \mathrm{rpm}$ and 30\% w/w BTX as feed) with different surfactant concentrations are presented in Figs. (1 and 2). An emulsion containing low surfactant concentrations $(0.5 \% \mathrm{w} / \mathrm{v})$ is not very stable and results in a phase separation within a short period of time. The mean droplets diameter declines from about $20 \mathrm{~nm}$ to $15 \mathrm{~nm}$ as the surfactant concentration increases from 0.5 to $1.5 \% \mathrm{w} / \mathrm{v}$ and no change in average droplet diameter and drop size distribution have been observed with further increase in surfactant concentration up to $2.5 \% \mathrm{w} / \mathrm{v}$. So in rest of the experiments the surfactant concentration is kept at $2.0 \% \mathrm{w} / \mathrm{v}$, which provides stable emulsion with a narrow drop size distribution (Fig. 2).

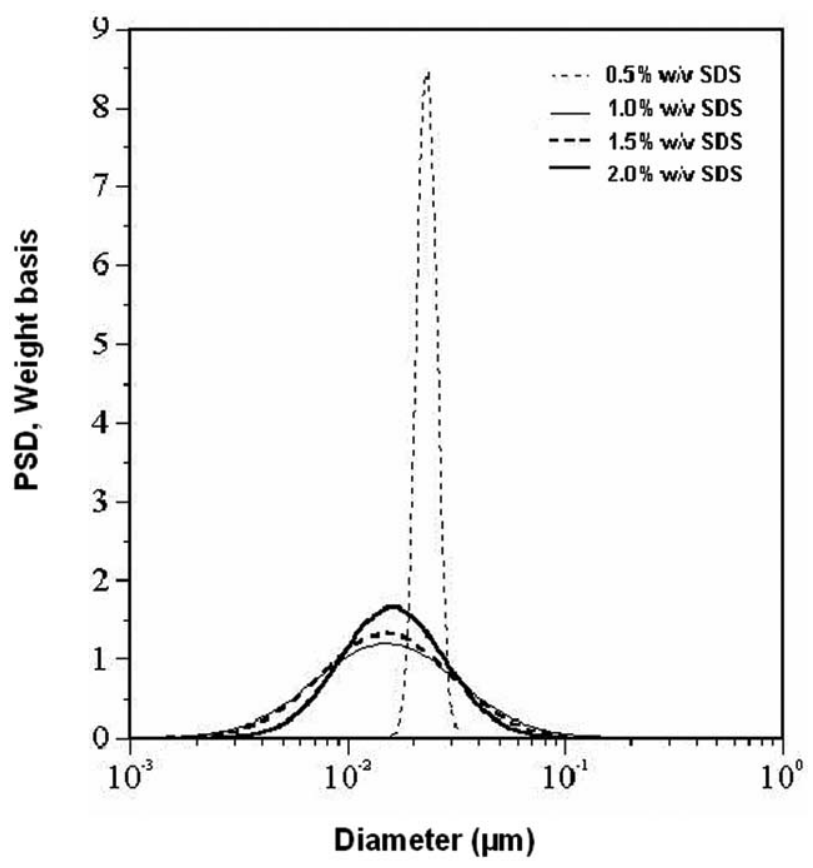

Fig. (2). Effect of surfactant concentration on internal droplets size distribution (log-normal).

From Fig. (3) it is found that there is significant increase of the backscattering intensity in the top part $(75 \%)$ of all emulsion samples whereas the backscattering intensities of the middle and bottom parts (55\%) have been decreased. It indicates that the top part of the emulsion has become dense and the droplet sizes have increased whereas the middle and the bottom parts of the emulsion samples have become thinner. It is a typical creaming process which leads to flocculation and coalescences of an emulsion and increase the size of the droplets. Creaming effect has been minimised in the emulsion with $2.0 \% \mathrm{w} / \mathrm{v}$ surfactant concentration.

\section{Effect of Feed Phase Concentration}

When the feed composition has been varied keeping lower phase $2.0 \% \mathrm{w} / \mathrm{v}$ aqueous SDS solution constant, it has been observed that with increasing BTX concentration as well as with decreasing $n$-heptane concentration in feed phase, interfacial tension is gradually decreasing and internal droplets size is also gradually reducing along with interfacial tension in feed phase (Fig. 4). From Fig. (5), it has been found that at all feed phase compositions the drop size distribution is uniform, symmetrical and shifted in the same manner. 


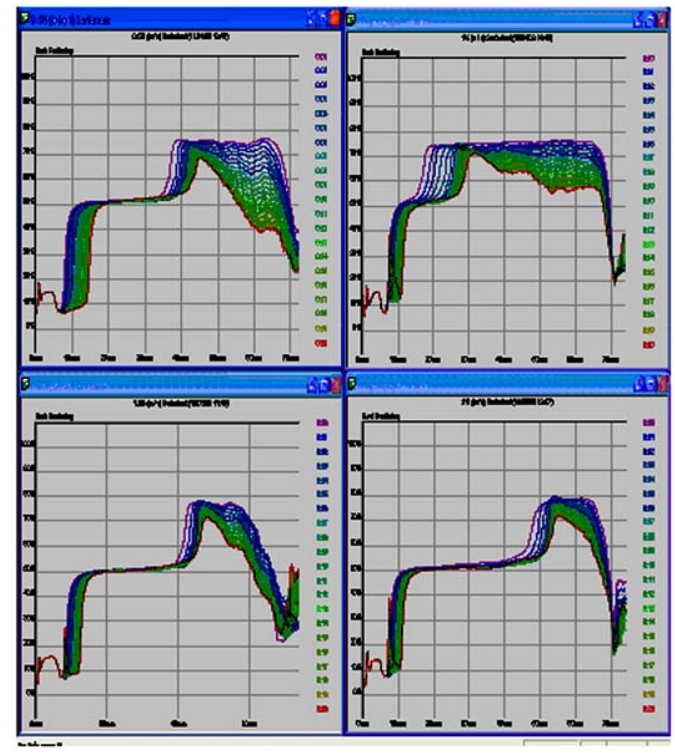

Fig. (3). Back scattering profile at different surfactant concentration.

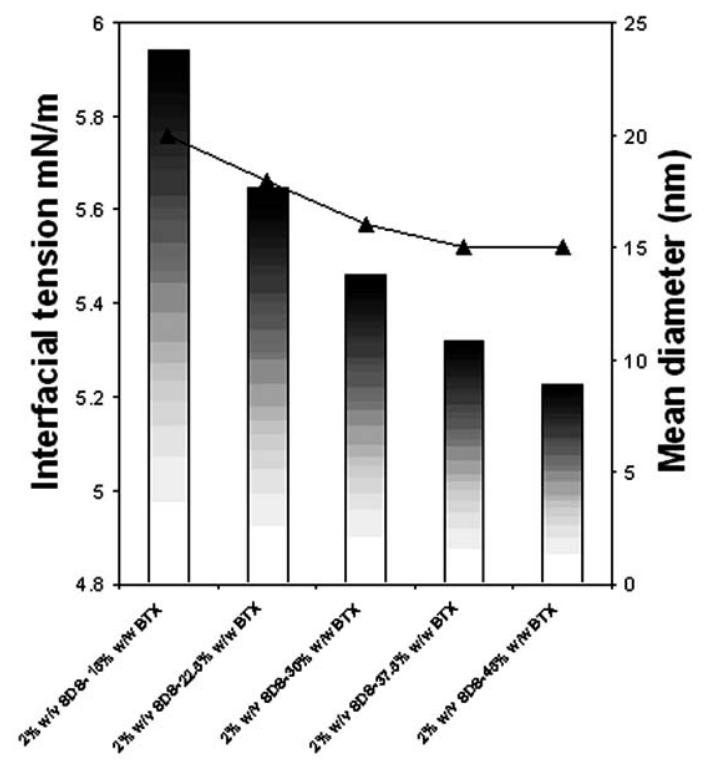

Fig. (4). Effect of feed phase composition on interfacial tension and internal droplets mean diameter.

\section{Effect of Stirrer Speed}

From Fig. (6) it is found that in the middle part of the sample, BS has been reduced from $75 \%$ to $60 \%$ for the emulsions prepared at $13500 \mathrm{rpm}$ and $9500 \mathrm{rpm}$ respectively. This indicates that the average droplet size of the emulsion sample has changed due increase of creaming with stirrer speed. Emulsion prepared at $13500 \mathrm{rpm}$ and $9500 \mathrm{rpm}$ are found unstable as the BS profile is moving downward with time. Migration velocities of clarification front are also very high $(2.45 \mathrm{~mm} / \mathrm{min}$ and $1.46 \mathrm{~mm} / \mathrm{min})$. From photomicrographs (Fig. 7) and internal droplet size distributions (Fig. 8) it is found that the droplet diameter of the dispersed emulsion is in the range of $10-80 \mu \mathrm{m}$ and those of the internal droplets are in the range of $0.001-0.1 \mu \mathrm{m}$. However, the dispersed emulsion drops prepared at $6500 \mathrm{rpm}$ contain

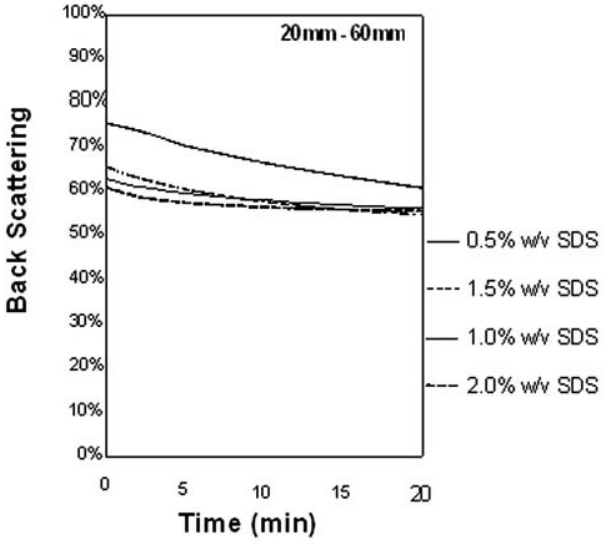

relatively less number of internal droplets (Fig. 7a) than those prepared at $9500 \mathrm{rpm}$ (Fig. 7b). Distefano et al. [20] found that the number and size of internal droplets in multiple emulsions are a function of agitation rate used to prepare the emulsion. From Fig. (8), which shows log normal as well as cumulative internal droplet size distribution, it has been observed that emulsions prepared at $6500 \mathrm{rpm}$ have a narrow size distribution with an internal droplet mean diameter of $0.016 \mu \mathrm{m}$. Emulsion prepared at $13500 \mathrm{rpm}$ and $9500 \mathrm{rpm}$ yield broader droplet size distribution but almost the same mean diameter $(0.015 \mu \mathrm{m})$.

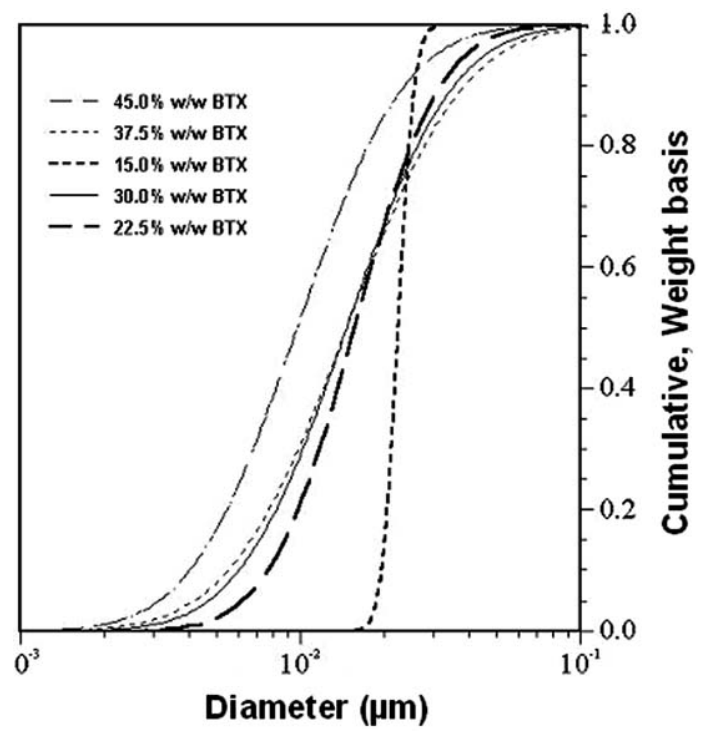

Fig. (5). Effect of feed phase composition on internal droplets size distribution (cumulative).

\section{Effect of Different Carriers}

From the literature it has been found that in presence of carriers, like $\mathrm{Ag}^{+}$ion $\left(0.05 \mathrm{~mol} / \mathrm{dm}^{3}\right)$ or $\beta C D(1.5 \mathrm{wt} \%)$, the separation factor for the toluene-n-heptane system is very 

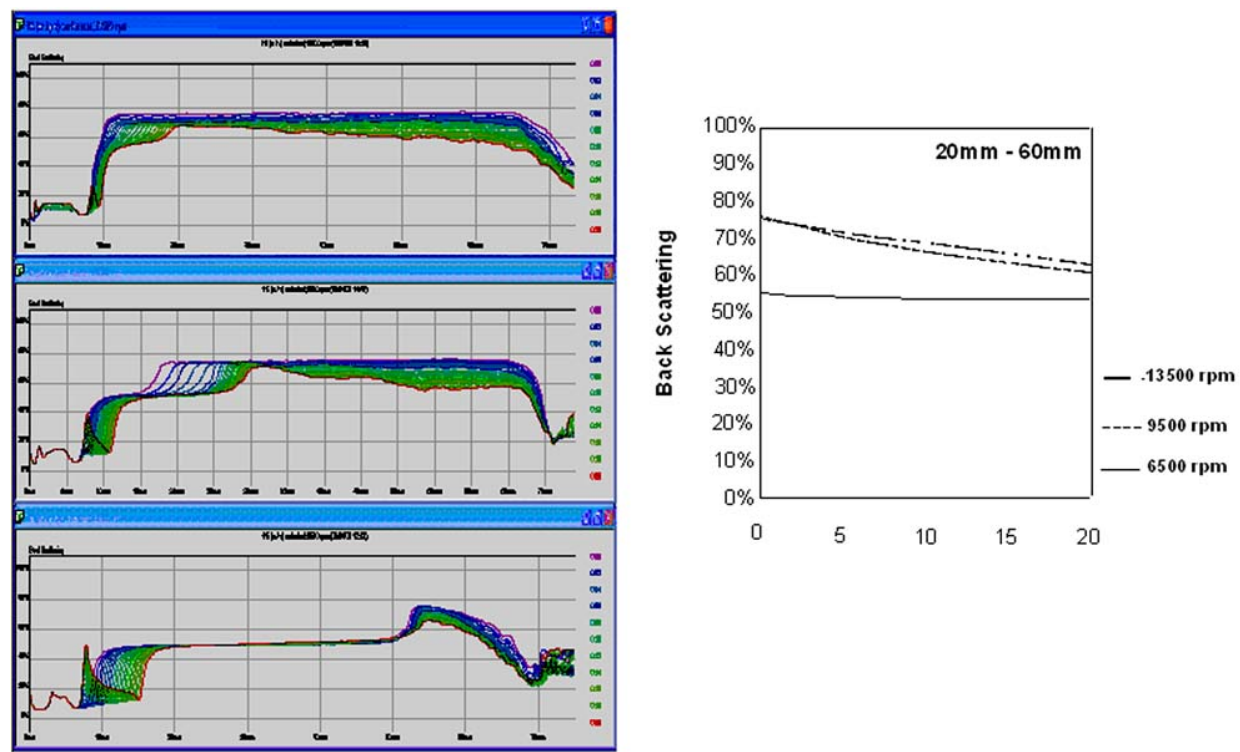

Fig. (6). Back scattering profile at different stirrer speed.

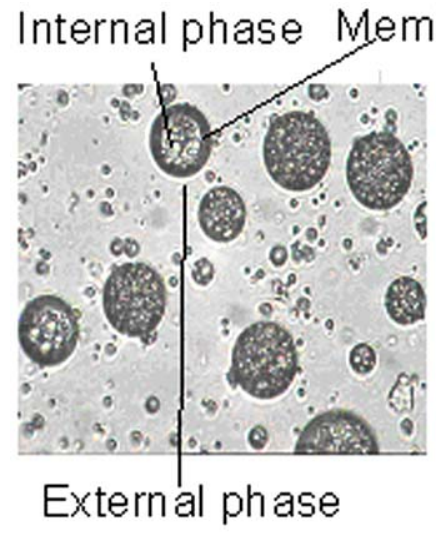

(a)

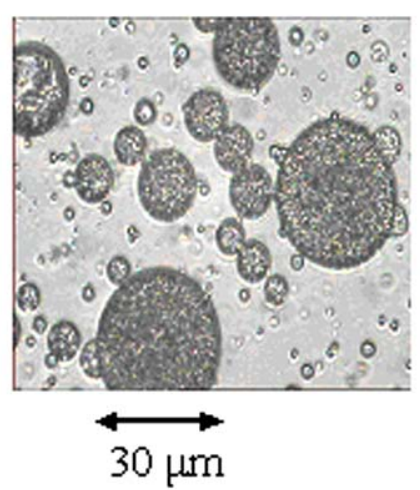

(b)

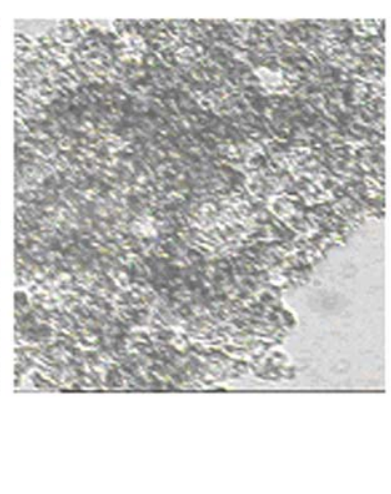

(c)

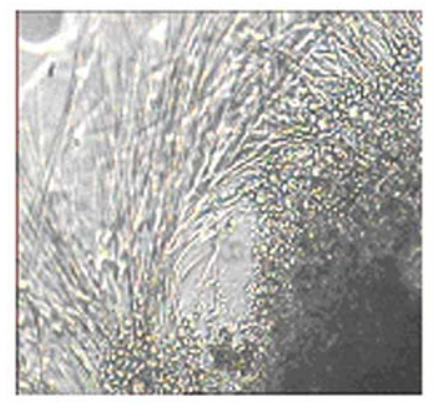

(d)

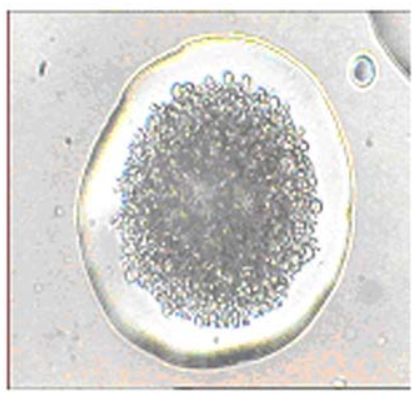

(e)

Fig. (7). Photomicrograph of emulsion prepared at (a) $6500 \mathrm{rpm}(\mathbf{b}) 9500 \mathrm{rpm}(\mathbf{c}) 13500 \mathrm{rpm}(\mathbf{d})$ with $\mathrm{Ag}^{+}$carrier at $6500 \mathrm{rpm}(\mathbf{e})$ with $\beta \mathrm{CD}$ carrier at $6500 \mathrm{rpm}$.

high, 16 and 11 respectively [10,11]. Therefore BS profiles have been studied with emulsion containing $\mathrm{Ag}^{+}$ion and $\beta C D$. It has been found (Fig. 9) that creaming effects have been reduced in presence of carriers.

It is known that strong electrolytes added to the aqueous phase make the electrical double layer thin and that the rates of aggregation resulting from this effect are the same in every electrolyte solution, which has a concentration higher than $0.01 \mathrm{~mol} / \mathrm{dm}^{3}[21]$. Photomicrograph (Fig. 7d) also shows that incorporation of strong electrolyte $\left(\mathrm{Ag}^{+}\right.$ion) in the aqueous (membrane) phase increases membrane breakage, resulting into the rapid transfer of internal feed phase to external phase whereas the $\beta C D$ containing emulsion (Fig. 7e) is quite stable. 


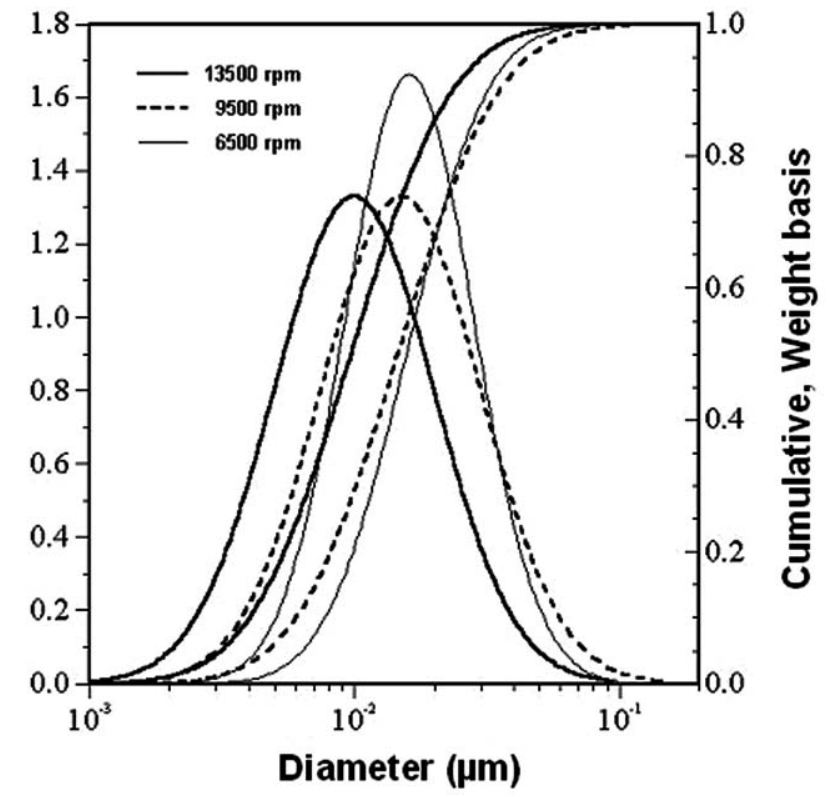

Fig. (8). Effect of stirrer speed on internal droplets size distribution (log-normal and cumulative).

\section{Long Term Stability}

For molecules and particles that are small enough, a high zeta potential will confer stability, i.e. the solution or dispersion will resist aggregation. When the potential is low, attraction exceeds repulsion and the dispersion will break and flocculate. So, colloids with high zeta potential (negative or positive) are electrically stabilized while colloids with low zeta potentials tend to coagulate or flocculate.

Here droplets of the emulsions are found to be negatively charged, as the zeta potential of the emulsion is approximately $-30.8 \mathrm{mV}$ (with $2.0 \% \mathrm{w} / \mathrm{v}$ SDS in membrane phase). The electrophoretic mobility is also measured with emulsions up to $20 \mathrm{~min}$ at a constant temperature of $25^{\circ} \mathrm{C}$. No changes in zeta potential and electrophoretic mobility are observed.

\section{Extraction of Aromatics}

Using optimum conditions (feed phase concentration $30 \% \mathrm{w} / \mathrm{w}$ BTX, SDS concentration $2.0 \% \mathrm{w} / \mathrm{v}$ and $6500 \mathrm{rpm}$ ) a stable emulsion is prepared, which is used for the separation of BTX from n-heptane in a synthetic feed mixture. The values of $R$ (ratio of the volume of the surfactant solution to that of the feed phase in emulsion) and $K$ (ratio of the volume of the solvent to that of the emulsion) are fixed at 0.5 and 3 , respectively.

It has been found that $35-70 \%$ extraction of BTX is possible within $12 \mathrm{~min}$ and maximum separation factors are 4.5 at 6 min (benzene), 3.5 at $2 \mathrm{~min}$ (toluene) and 3.1 at 2 min (xylene) of operation respectively (Fig. 10). After the maximum has been attained, the separation factor decreases with further contact because the amount of the less permeable (n-heptane) in the emulsion phase becomes larger than that of the more permeable (BTX). Besides, some parts of the membranes become unstable and break with further contact. The less permeable species of the inner feed mixture dissolves directly into the solvent phase without passing through the selective membranes. As a result the separation factor tends to decrease.

Experiments have been carried out to separate BTX and n-heptane mixture using $\mathrm{Ag}^{+}$ion $\left(0.05 \mathrm{~mol} / \mathrm{dm}^{3}\right)$ and $\beta C D$ $(1.5 \% \mathrm{w} / \mathrm{v})$ containing emulsion. It has been found that more than $40-80 \%$ recovery of aromatics are possible within 8-10 min of operation and the maximum separation factors for benzene are around 18.8 at $1 \mathrm{~min}$ and 10.12 at $4 \mathrm{~min}$ of operation respectively (Fig. 11a \& 11b).

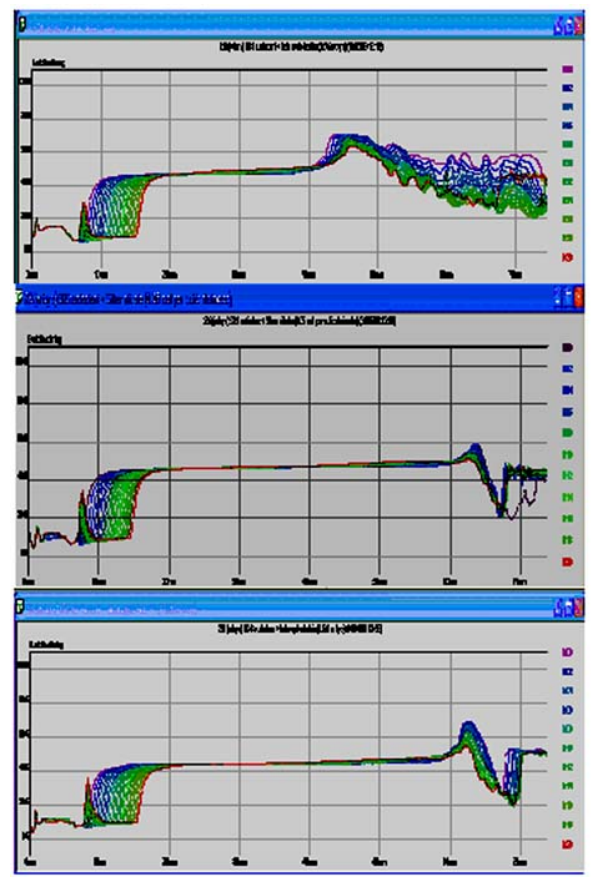

Fig. (9). Back scattering profile in presence of different carriers.

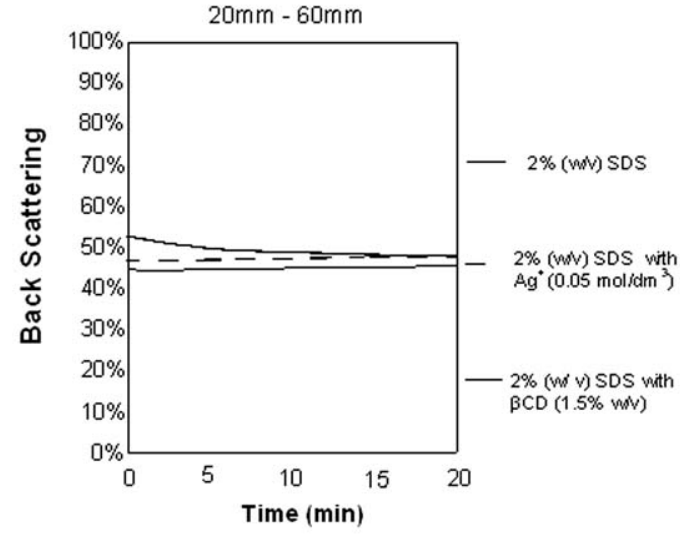



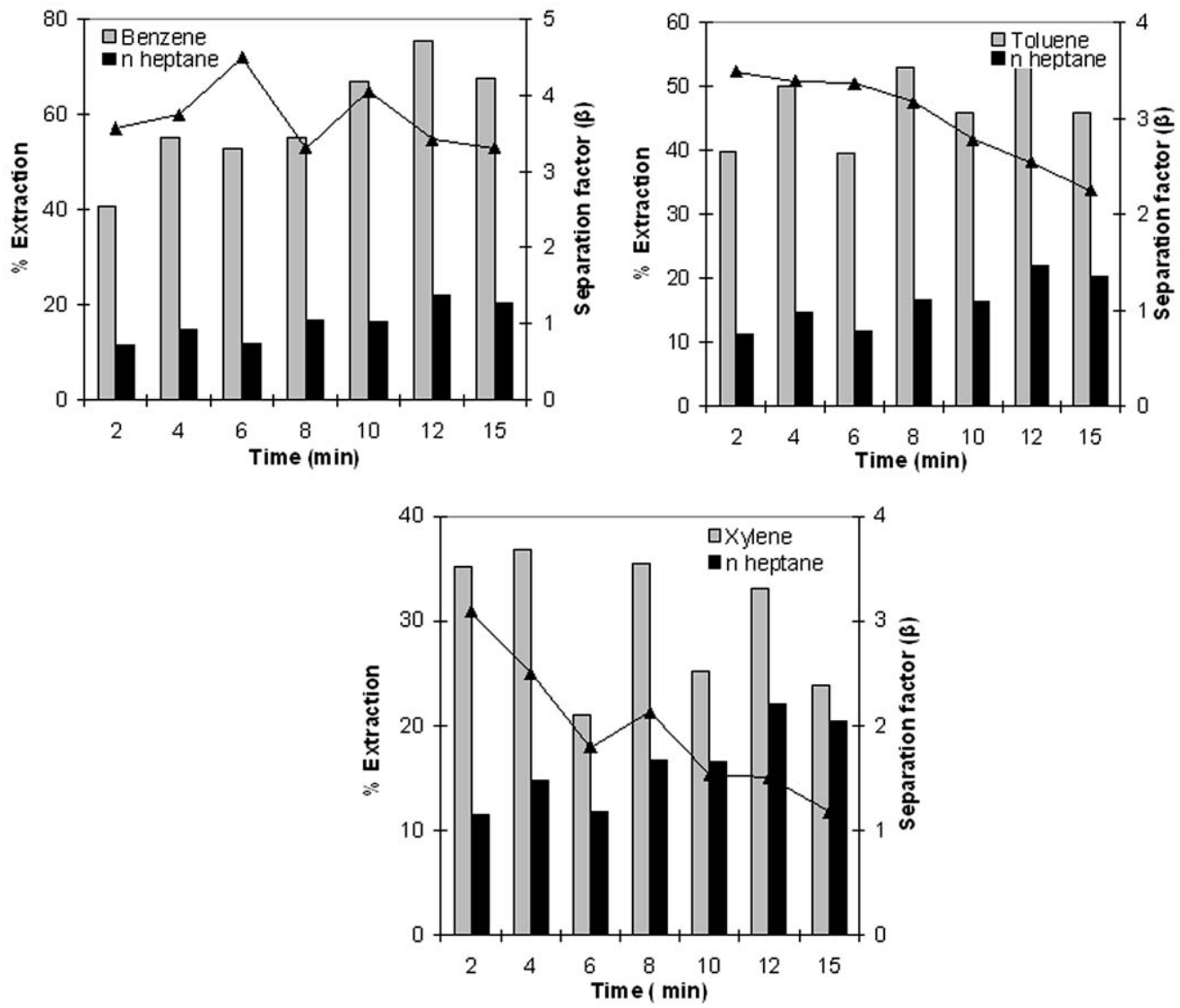

Fig. (10). Separation factor and \% extraction with conventional o/w/o- emulsion.
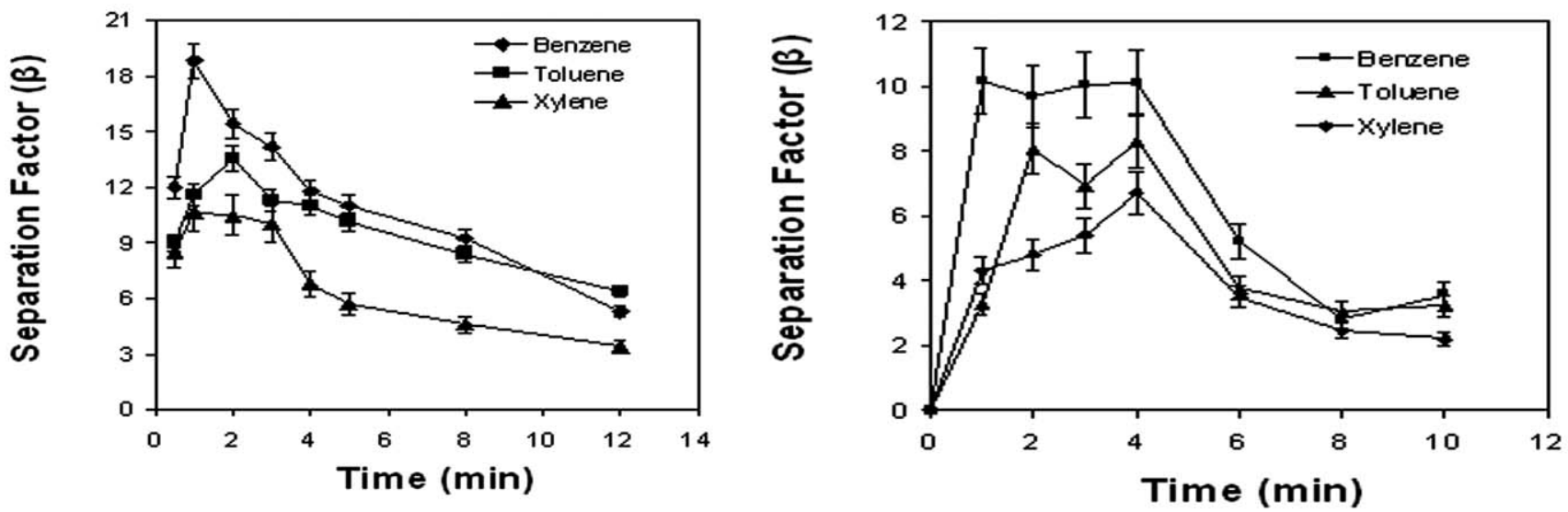

Fig. (11). Effect of different carriers on separation factor.

\section{CONCLUSIONS}

An important problem in the practical application of the ELM process is the stability of the liquid membranes. The instability of liquid membrane leads to breakage and, hence, unselective release of already separated compounds. So it is important to obtain information about the swelling, the

breakup, and the coalescence of dispersed drops. Swelling and globule rapture can be controlled by proper selection of emulsion composition and parameters during emulsification process. This paper describes the stability behavior under a wide variety of operating conditions as are surfactant and feed phase concentrations, stirrer speed and also in presence of different carriers. From this study it has been found that 
uniformly distributed stable emulsion can be obtained by selecting optimum conditions, which will provide a high separation factor and a higher mass transfer rate for the separation of BTX from n-heptane. Membrane leakage or rupture can be minimised through the use of bifunctional surfactants, which act as both emulsifier and extractant, and additives (e.g., polymer) to impact elasticity of membrane.

\section{ACKNOWLEDGEMENTS}

Authors wish to acknowledge the "Landesforschungsschwerpunkt" Advanced Materials Engineering and the Alexander von Humboldt-Stiftung, Germany, for financial support.

\section{ABBREVATIONS}

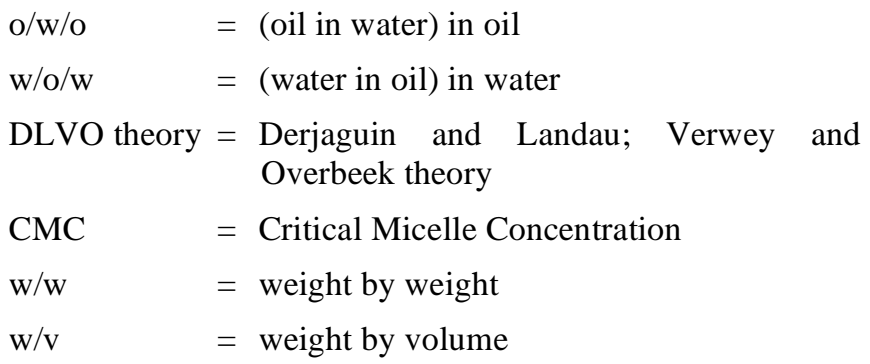

\section{REFERENCES}

[1] N. N. Li, "Separation of hydrocarbons by liquid membrane permeation", Ind. Eng. Chem. Process Des. Dev., vol. 10, pp. $215-$ 221, 1971.

[2] S. K. Ihm, Y. H. Jeong, and Y.S. Won, "Experimental investigation of the oil/water/oil liquid-membrane separation of toluene and nheptane I. Batch test of a mixer-settler", J. Membr. Sci., vol. 32, pp. 31-46, 1987.

[3] R. Krishna, A.N. Goswami, and A. Sharma, "Effect of emulsion breakage on selectivity in the separation of hydrocarbon mixtures using aqueous surfactant membranes", J. Membr. Sci., vol. 34, pp. 141-145, 1987.

[4] A.N. Goswami, and B.S. Rawat, "Studies on the permeation of aromatic hydrocarbons through liquid surfactant membranes", $J$. Membr. Sci., vol. 24, pp. 145-168, 1985.

[5] A. Sharma, A.N. Goswami, B.S. Rawat, and R. Krishma, "Effect of surfactant type on selectivity for the separation of 1-methylnaphtalene from dodecane using liquid membranes", J. Membr. Sci., vol. 32, pp. 19-30, 1987.
[6] S.K. Sharma, and A. N. Goswami, "Dearomatisation of a refinery kerosene by liquid surfactant membranes - prediction of extraction rates", J. Membr. Sci., vol. 88, pp. 69-76, 1994.

[7] M. Ulbrich, R. Marr, and J. Draxler, "Selective separation of organic solutes by aqueous liquid surfactant membranes", $J$. Membr. Sci., vol. 59, pp. 189-203, 1991.

[8] R. Egashira, H. Habaki, and J. Kawasaki, "Decrease in aromatics content in motor gasoline by o/w/o emulsion liquid", Sekiyu Gakkai Shi, vol. 40, pp. 107-114, 1997.

[9] S. J. Kim, H. K. Lee, and H. J. Jeong, "Permeability of hydrocarbon components through liquid surfactant membrane", $J$. Korean Ind. Eng. Chem., vol. 13, pp. 173-178, 2002.

[10] M. Chakraborty, and H.-J. Bart, "Separation of toluene and nheptane using $\mathrm{Ag}^{+}$- containing emulsion liquid membranes", Chem. Eng. Technol., vol. 28, pp. 1-7, 2005.

[11] M. Chakraborty, P. I. Mitseva, and H.-J. Bart, "Selective separation of toluene from n-heptane via emulsion liquid membranes containing substituted cyclodextrins as carriers", Sep. Sci. Technol., vol. 41, pp. 3539-3552, 2006.

[12] J. Shere, and H.M. Cheung, "Effect of preparation parameters on leakage in liquid surfactant membrane systems", Sep. Sci. Technol., vol. 23, pp. 687-701, 1988.

[13] W. Hou, and K.D. Papadopoulos, "Stability of water-in-oil-inwater type globules", Chem. Eng. Sci., vol. 51, pp. 5043-5051, 1996.

[14] A. J. Yan, and R. Pal, "Osmotic sweling behaviour of globules of w/o/w emulsion liquid membranes", J. Membr. Sci., vol. 190, pp. 79-91, 2001.

[15] M. Chakraborty, C. Bhattacharya, and S. Datta, "Study of the stability of (w/o)/w-type emulsion during the extraction of nickel (II) via emulsion liquid membrane", Sep. Sci. Technol. vol. 39, pp. $1-17,2004$

[16] A. Avranas, G. Stalidis, and G. Ritzoulis, "Demulsification rate and zeta potential of o/w emulsions", Colloid Polym. Sci., vol. 266, pp. 937-940, 1988

[17] B. Reichardt, "Solvatochromic dyes as solvent polarity indicators", Chem. Rev., vol. 94, pp. 2319-2358, 1994.

[18] M. Chakraborty, and H.-J. Bart, "Emulsion liquid membranes: role of internal droplet size distribution on toluene/n-heptane separation", Colloids Surf., A, vol. 272, pp. 15-21, 2006.

[19] C. Esposito, P. Colicchio, A. Facchiano, and R. Ragone, "Effect of a weak electrolyte on the critical micellar concentration of sodium dodecyl sulfate", J. Colloid Interface Sci., vol. 200, pp. 310-312, 1998.

[20] F.V. Distefano, O.M. Shaffer, M.S. El-Aasser, and J.W Vanderhoff, "Multiple oil-in-water-in-oil emulsions of extremely fine droplet size", J. Colloid Interface Sci., vol. 92, pp. 269-272, 1983.

[21] A. Kitahara, and A. Watanabe, Interfacial Electrical Phenomena, Kyoritsu Shuppan Tokyo: Tokyo, 1972.

(C) Barad et al.; Licensee Bentham Open.

This is an open access article licensed under the terms of the Creative Commons Attribution Non-Commercial License (http://creativecommons.org/licenses/by-nc/3.0/) which permits unrestricted, non-commercial use, distribution and reproduction in any medium, provided the work is properly cited. 